\title{
Electrostatic Filters to Reduce COVID-19 Spread in Bubble CPAP: An in vitro Study of Safety and Efficacy
}

\author{
Jonathan W. Davis ${ }^{\text {a, b }}$ J. Jane Pillow ${ }^{c}$ Matthew N. Cooper ${ }^{d}$ Mar Janna Dahl ${ }^{c}$ \\ ${ }^{a}$ Neonatology, Child and Adolescent Health Service, Hospital Avenue, Nedlands, WA, Australia; ${ }^{b}$ Medical School, \\ The University of Western Australia, Perth, WA, Australia; ' $S$ chool of Human Sciences, The University of Western

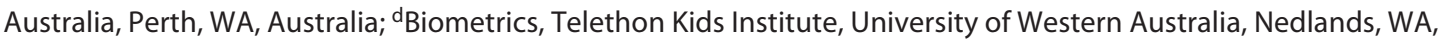 \\ Australia
}

\section{Keywords}

Electrostatic filters - Continuous positive airway pressure

Noninvasive ventilation $\cdot$ Pressure $\cdot$ Infant $\cdot$ Newborn

\begin{abstract}
Background: Bubble CPAP may be used in infants with suspected or confirmed COVID-19. Electrostatic filters may reduce cross infection. This study aims to determine if including a filter in the bubble CPAP circuit impacts stability of pressure delivery. Methods: A new electrostatic filter was placed before (pre) or after (post) the bubble CPAP generator, or with no filter (control) in an in vitro study. Pressure was recorded at the nasal interface for $18 \mathrm{~h}\left(6 \mathrm{~L} / \mathrm{min} ; 7 \mathrm{~cm} \mathrm{H} \mathrm{H}_{2} \mathrm{O}\right)$ on 3 occasions for each configuration. Filter failure was defined as pressure $>9 \mathrm{~cm} \mathrm{H}_{2} \mathrm{O}$ for 60 continuous minutes. The filter was weighed before and after each experiment. $R \boldsymbol{e}$ sults: Mean (SD) time to reach the fail point was 257 (116) min and 525 (566) min for filter placement pre- and postCPAP generator, respectively. Mean pressure was higher throughout in the pre-generator position compared to control. The filter weight was heavier at end study in the precompared to the post-generator position. Conclusions: Placement of the filter at the pre-generator position in a bub-
\end{abstract}

karger@karger.com www.karger.com/neo

(c) 2020 S. Karger AG, Base

Karger' ble CPAP circuit should be avoided due to unstable mean pressure. Filters are likely to become saturated with water over time. The post-generator position may accommodate a filter, but regular pressure monitoring and early replacement are required.

(c) 2020 S. Karger AG, Basel

\section{Introduction}

SARS-CoV-2 originated in Wuhan, China, in November 2020 [1]. The clinical disease, COVID-19, was declared a global pandemic by WHO in March 2020 [2]. Data on neonatal infection with SARS-CoV-2 are limited [3-5]. The need for respiratory support in infants with COVID-19 is uncertain.

Continuous positive airway pressure (CPAP) has been a cornerstone treatment of neonatal respiratory distress syndrome for $>40$ years. CPAP use has extended in recent years to include infants with viral respiratory disease [6]. Bubble $\mathrm{CPAP}$ is a popular means of providing respiratory support in these infants. The expiratory limb of the bubble CPAP circuit vents through an underwater seal [7], creating bubbles. The resulting pressure oscillations are transmitted 
back to the nares and to the lung; hence, the bubbling delivers a variable rather than constant pressure [8]. These pressure oscillations (frequency) may improve acute respiratory mechanics compared to constant delivery pressure consequent to recruitment of atelectatic alveoli [7-11].

CPAP generates aerosols and therefore may promote transmission of viral particles $[12,13]$. Electrostatic filters remove viruses from expired gas, offering protection to health care staff and are recommended in international guidelines [14]. Manufacturers of electrostatic filters recommend electrostatic filter replacement every $24 \mathrm{~h} \mathrm{[15].}$ One reason for these recommendations is the possibility of moisture saturation of the electrostatic filter which would increase resistance to airflow, increasing circuit pressure and work of breathing. We hypothesized that progressive moisture saturation of an electrostatic filter placed in humidified bias flow would result in increased circuit pressure. We aimed to determine how the placement and position of an electrostatic filter in a bubble CPAP circuit impacts the magnitude and stability of the delivered pressure in an in vitro model.

\section{Methods}

An in vitro study was conducted at the University of Western Australia in April 2020. A simulated in vitro neonatal lung on a bubble CPAP model was created by connecting a test lung (Dräger, Lubeck, Germany) to a bubble CPAP generator (Fisher \& Paykel, Auckland, New Zealand). An infant nasal CPAP cannula (Size 4, Hudson RCI, Teleflex, Morrisville, NC, USA) was interfaced between the bias flow circuit and the test lung. Humidified bias flow (MR290; Fisher \& Paykel, Auckland, New Zealand) was set at 6 L/ min (of air). CPAP was measured at the proximal pressure line connector of the CPAP cannula using a physiological pressure transducer and dome (MLT844; ADInstruments, Sydney, Australia). The bubble CPAP generator and humidifier were set below the test lung, which was maintained on a radiant-heated neonatal cot (Cosy-Cot; Fisher and Paykel, Auckland, New Zealand). The CPAP generator was positioned below the circuit to promote free water drainage into the generator throughout the experiment without regular intervention. The cot warmer was set at $75 \%$ of maximum heat setting on the manual mode. Environmental ambient temperature was $23.9-24.7^{\circ} \mathrm{C}$ throughout the recording periods.

\section{Filter Placement}

A DAR ${ }^{\mathrm{TM}}$ pediatric-neonatal electrostatic filter (size: small; Covidien, Mansfield, MA, USA) was placed at one of 2 points in the breathing circuit: on the CPAP probe immediately before the exit of the bias flow into the water column (pre-generator; Fig. 1b) or at the bias flow exit point, normally used as the water inlet (post-generator; Fig. 1c). A new filter was used for each experimental repeat and was weighed before and after each trial. A bubble CPAP circuit without a filter was used as the control (Fig. 1a) for the 2 experimental arms. Each filter position and control was repeated 3 times.

\section{Signal Recording}

The pressure signal was amplified, digitized (ML880; PowerLab ADInstruments, Bella Vista, NSW, Australia), and recorded continuously for $18 \mathrm{~h}$ (LabChart 8, ADInstruments, Bella Vista, NSW, Australia) onto a laptop computer. This duration was chosen to reflect likely clinical exposure while remaining within the manufacturer's maximum recommended period for use $(24 \mathrm{~h})$. Pressure and frequency data were collected at 5-min intervals in 10 -s epochs at a sampling frequency of $1 \mathrm{kHz}$.

\section{Analysis}

The filter position fail point was defined as a mean pressure exceeding $9 \mathrm{~cm} \mathrm{H}_{2} \mathrm{O}$ for $>60$ continuous minutes. Mean pressure variability in a no-leak bubble CPAP system is $25 \%$ greater than the set pressure [16]. Our fail point allowed a $25 \%$ increase on top of the set pressure to the nearest integer. The mean pressure and pressure difference $(\Delta P)$ of the bubble oscillations for each group (pre-generator, post-generator, and control) were compared across the $18 \mathrm{~h}$ using a two-way repeated measures ANOVA with Holm-Sidak post hoc correction. The frequency oscillations, unique to bubble CPAP, were assessed by transforming the mean pressure time series recording into the frequency domain using power spectral analysis. The mean frequency at the maximum power signal of the 3 circuit configurations was compared using a two-way repeated measures ANOVA with Holm-Sidak post hoc correction. Filter weight and water volume in the circuit and overflow were compared by an unpaired Student's $t$ test and one-way ANOVA, respectively. $p$ values were assessed at a 0.05 significance level by SigmaPlot (Systat, Inc., Santa Clara, CA, USA).

\section{Results}

\section{CPAP Fail Point}

Failure to maintain mean pressure below $9 \mathrm{~cm} \mathrm{H}_{2} \mathrm{O}$ occurred for 3 tests of the pre-generator and 2 of the 3 tests of the post-generator position. The mean (SD) time to the fail point in pre-generator position was 257 (116) min and 525 (566) min for post-generator position. Mean pressure did not reach the fail point in the control group.

\section{Mean Pressure, $\Delta P$, and Frequency}

The mean pressure with the filter in the pre-generator position increased progressively throughout the experiment and was significantly greater than control in 15 of the $18 \mathrm{~h}$ of the study. $\Delta P$ was lower with the filter in the pre-generator position from $3 \mathrm{~h}$ after study commencement. In contrast, the increase in mean pressure with the filter at the post-generator position was not significant compared to control. Post-generator $\Delta P$ was significantly lower than control only at hours 8,12 , and 17 . The mean frequency at maximum power was similar for all circuit configurations (Fig. 2a-f). 


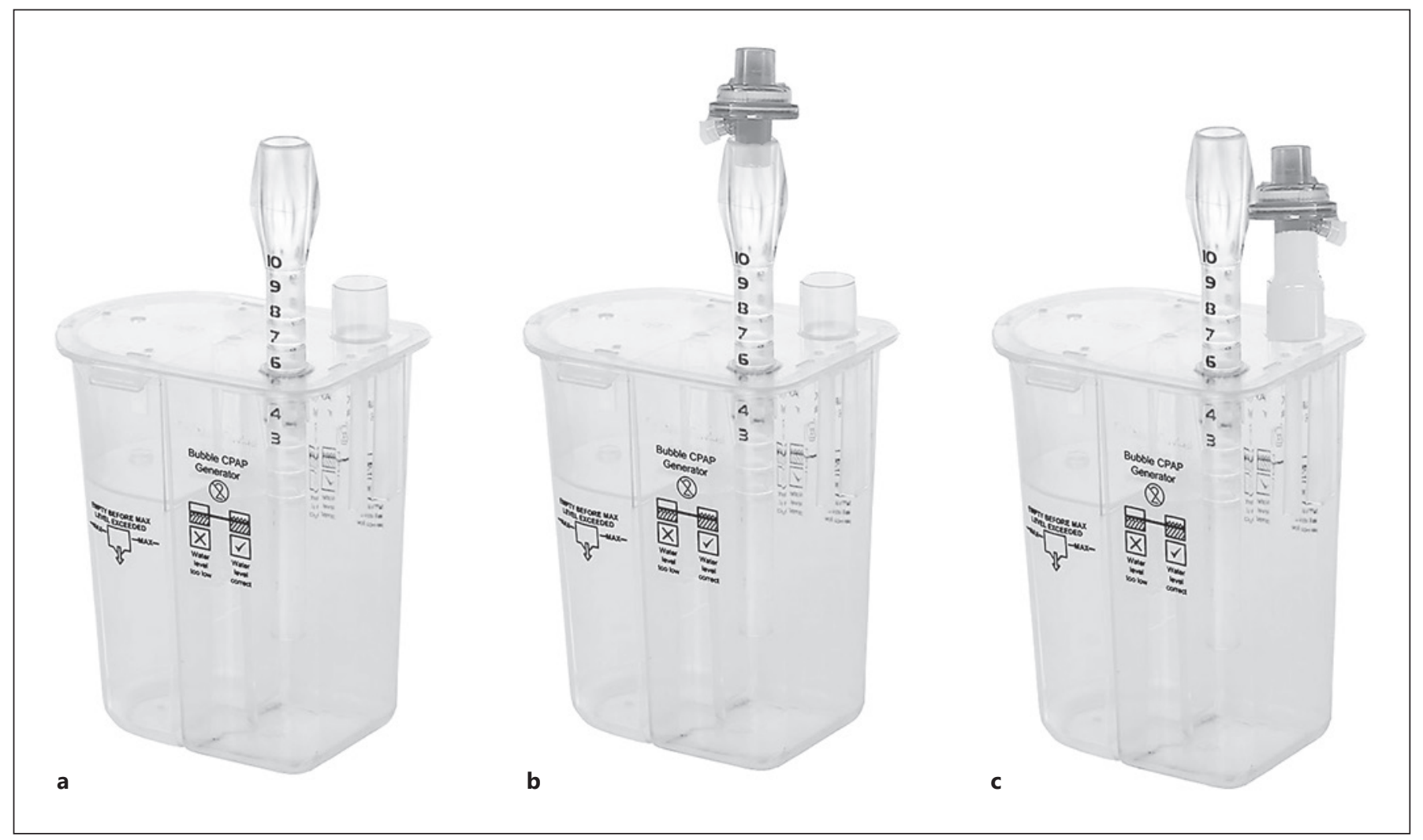

Fig. 1. Filter placement. Control, standard setup (a); pre-generator expiratory limb (b); and post-generator at point of flow exit into environment (c).

Table 1. Filter weights and volumes of water removed from the circuit

\begin{tabular}{|c|c|c|c|}
\hline & \multicolumn{3}{|c|}{ Filter position } \\
\hline & $\begin{array}{l}\text { control } \\
(n=3)\end{array}$ & $\begin{array}{l}\text { pre-generator } \\
(n=3)\end{array}$ & $\begin{array}{l}\text { post-generator } \\
(n=3)\end{array}$ \\
\hline \multicolumn{4}{|l|}{ Baseline } \\
\hline Filter dry weight, $g$ & - & $8.8 \pm 0.1$ & $8.9 \pm 0.1$ \\
\hline \multicolumn{4}{|l|}{ End study } \\
\hline Filter weight, $g$ & - & $11.9 \pm 0.2^{\dagger}$ & $10.8 \pm 0.1^{\dagger, \S}$ \\
\hline Water removed from circuit, $\mathrm{mL}$ & $4.0(3.0)$ & $2.5(3.5)$ & $2.0(1.5)$ \\
\hline Water removed from overflow, $\mathrm{mL}$ & $0(10)$ & $1(6)$ & $160(20)^{*}$ \\
\hline
\end{tabular}

Median (range). ${ }^{\dagger} p<0.05$ compared to dry weight (baseline) for same filter position. ${ }^{\S} p<0.05$ compared to pre-generator at study end. $* p<0.05$ compared to control and pre-generator.

\section{Filter Weight}

Filter weights before and after use are reported in Table 1. for both circuit filter positions. The filter weight was significantly heavier in the pre-generator compared to the post-generator position at the end of the study. Sig- nificantly more water accumulated in the generator overflow in the post-generator positions compared to the pregenerator position and the control position. Inclusion of a filter did not alter the volume of water that accumulated in the CPAP circuit. 


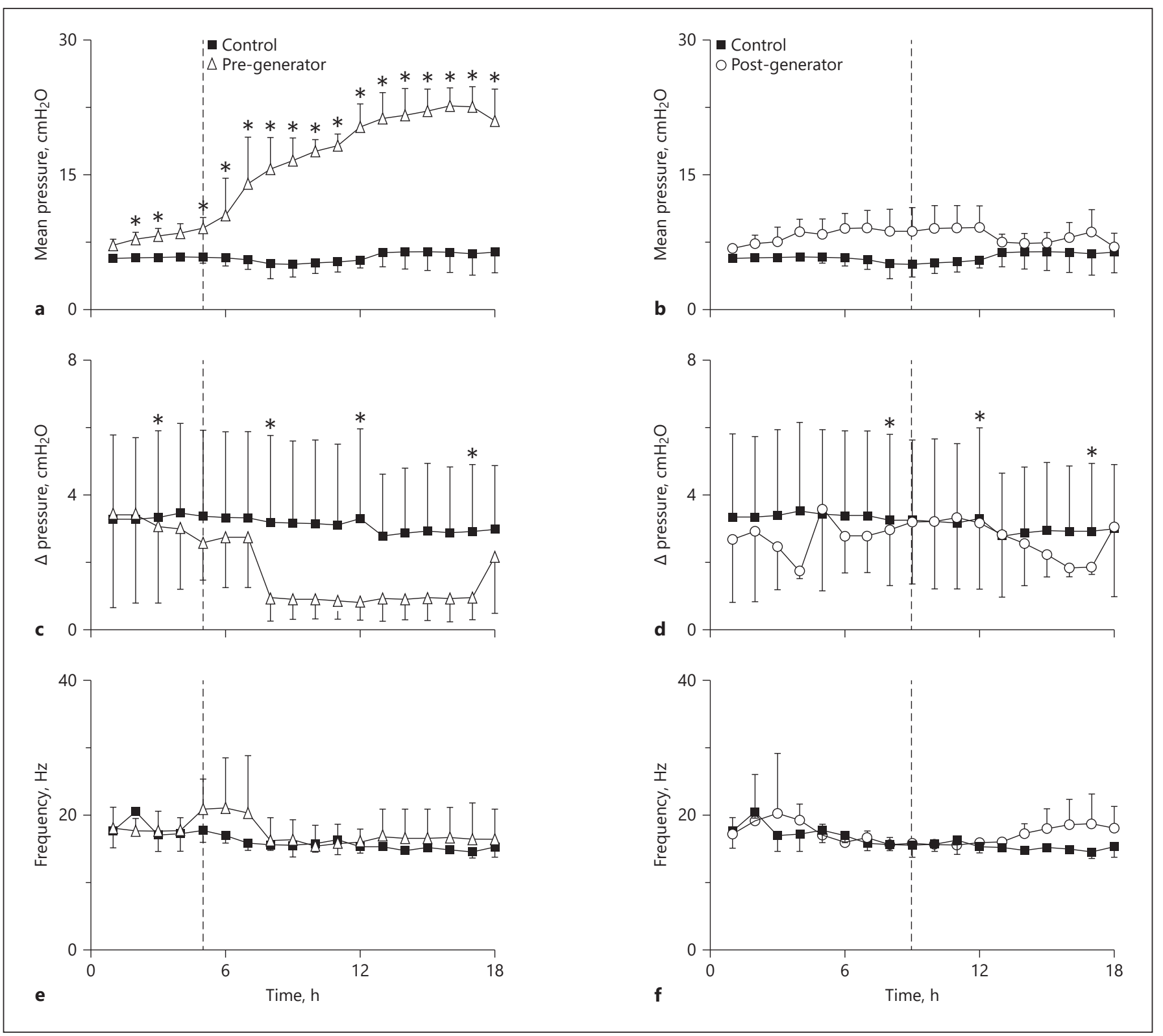

Fig. 2. Mean pressure (a-b), $\Delta \mathrm{P}(\mathbf{c}-\mathbf{d})$, and frequency (e-f) over time for the filter positions and control: no filter (none, black square), pre-generator (pre, open triangle), post-generator (post, open circle). Data points are mean (SD) for $n=3$ /group. The fail points for the respective filter position are represented by a vertical dashed line. ${ }^{*} p<0.05$.

\section{Discussion}

The placement of an electrostatic filter in a bubble CPAP circuit changes the stability of pressure delivery. Positioning of the filter either immediately before or after the bubble generator increases the mean pressure delivered above a predefined fail point. Filter failure occurs earlier and is sustained when the filter is positioned im- mediately before the CPAP generator, compared to later and intermittent failure when placed in the post-generator position (point of exit of flow into the environment). Incorporation of a filter did not change the mean frequency of the maximum power in the oscillatory pressure waveform. The filter become more saturated with water when positioned in the pre-generator versus post-generator position. 
Placement of a filter in a bubble CPAP circuit reduces water accumulation within the circuit; however, the filter increases in weight over time, indicative of water absorption by the filter. Filter saturation increases resistance [17]. This may explain the increased mean pressure and dampened pressure waveform with the filter in the pregenerator position. Microbial filters marginally increase the imposed work of breathing measured over 18 breaths across a range of non-humidified respiratory support devices [18]. In comparison, our recordings were in a humidified system and were conducted over an extended period $(18 \mathrm{~h})$; using this more clinically applicable setting we clearly show that time and humidification affect mean pressure when the circuit configuration includes an electrostatic filter, especially when the filter is positioned prior to the bubble generator.

Few studies report the volume of airway condensate in infants on CPAP. The estimated median exhaled rate of breath condensate production in moderately preterm infants receiving nasal CPAP is $0.07 \mathrm{~mL} / \mathrm{min}$ [19]. If extrapolated over $18 \mathrm{~h}$, the exhaled breath condensate would equate to $75 \mathrm{~mL}$ of additional liquid into the breathing circuit. This estimated condensate volume is substantially more than that measured in the experiments reported here. The lower volume of breath condensate in our study may be due to the in vitro nature of the study, which did not include a contribution of expired gas from the lung. The added contribution of humidified exhaled air may saturate the electrostatic filter sooner when used in the clinical setting. Thus, the clinician needs to be aware that filter changes may be required even sooner than suggested by our study to avoid potentially adverse increases in circuit pressure due to increased expiratory resistance through the saturated filter.

A highly variable or noisy pressure waveform is characteristic of bubble CPAP. Similar to high-frequency oscillatory ventilation, the amplitude of the bubble CPAP pressure waveform $(\Delta P)$ is a fundamental determinant of carbon dioxide clearance $[7,20]$. The variable pressure is also fundamental for stochastic recruitment of collapsed alveoli [7-11]. Bubble CPAP improved measures of acute respiratory mechanics and reduced lung injury compared to constantly delivered CPAP in preterm lambs [7]. Damping of the $\Delta P$ with the filter in the pre-generator position would reduce the efficacy of bubble CPAP for gas exchange and alveolar recruitment.

Although the in vitro nature of this study may be considered a limitation, such models are used widely for describing the performance of respiratory support devices, including neonatal respiratory support modalities $[16,18$, 21-24]. Our in vitro experimental setup was a sealed circuit,

Viral Filters Impact the Delivery of Pressure in Bubble CPAP measuring the stability of pressure without considering leak. Clinically, bubble CPAP pressure delivery is determined by the bias flow and degree of leak at the nares, as well as the degree of mouth closure [16]. Many neonatal units aim to minimize leak by using chin straps (to keep the mouth closed) and colloid dressings over the nares that not only reduce nasal trauma but also markedly reduce leak at the nasal interface. The instability of the delivered pressure over time should concern clinicians considering the use of such filters when treating premature infants with bubble CPAP, particularly when positioning the filter immediately before the bubble CPAP generator chamber.

The transmission of SARS-CoV-2 to health care workers is a major concern in the current pandemic [25]. Neonates are at risk of COVID-19, although evidence of infection is sparse. Newborns of mothers with confirmed or suspected COVID-19 require precautions as recommended in recent published international guidelines [26]. Filters reduced the expired viral load from ventilator circuits when tested in previous pandemics $[27,28]$ and are recommended by several international societies $[29,30]$. However, it is essential to consider how such filters impact the efficacy of the respiratory support and to identify required changes in clinical practice, such as frequency of filter exchange, to ensure safety of both health care workers and the patient.

We conclude that the addition of an electrostatic filter into the circuit of a bubble CPAP system must be undertaken with extreme caution. The clinical impact of such filters may be the unstable and unintended delivery of excessive airway pressure resulting in unwanted side effects such as air leak. Placement of a viral filter in the expiratory circuit immediately before the bubble CPAP generator chamber is not recommended. The excessive drift in mean pressure delivery and damping of the pressure waveform with the filter in this position presents a safety risk for the infant that outweighs the benefit of preventing cross infection. The addition of the filter at the flow exit point for the CPAP generator (post-generator) may be acceptable but requires monitoring of the pressure in the circuit at regular intervals. The manufacturer of this filter recommends changing it every $24 \mathrm{~h}$. Based on the data presented, changing the filter at least every $12 \mathrm{~h}$, and likely every $8 \mathrm{~h}$, should be considered when used in bubble CPAP.

\section{Statement of Ethics}

This paper is exempt from ethical committee approval as it was conducted in a laboratory without the participation of human or animal subjects. 


\section{Conflict of Interest Statement}

J.W. Davis, M.N. Cooper, and M.J. Dahl have no financial ties to the products in this study. J.J. Pillow has received unrestricted grants of equipment (humidifiers) and consumables (ventilator and CPAP circuits) for use in preclinical research from Fisher and Paykel Healthcare.

\section{Funding Sources}

The authors received no specific funding for this work.

\section{Author Contributions}

M.J. Dahl and J.W. Davis made substantial contributions to the study conception and design, acquisition, analysis, interpretation of data, drafting and revising the manuscript. M.N. Cooper made a substantial contribution to the analysis, interpretation of the data, and drafting and revising the article for submission. J.J. Pillow contributed to the study design, analysis, and interpretation of data and made a substantial contribution in revising the manuscript and approving for submission.

\section{References}

1 Mimouni F, Lakshminrusimha S, Pearlman SA, Raju T, Gallagher PG, Mendlovic J. Perinatal aspects on the covid-19 pandemic: a practical resource for perinatal-neonatal specialists. J Perinatol. 2020;40(5):820-6.

2 Jin Y, Yang H, Ji W, Wu W, Chen S, Zhang W, et al. Virology, epidemiology, pathogenesis, and control of COVID-19. Viruses. 2020 12(4):372.

3 Piersigilli F, Carkeek K, Hocq C, van Grambezen $\mathrm{B}$, Hubinont $\mathrm{C}$, Chatzis $\mathrm{O}$, et al. $\mathrm{COV}$ ID-19 in a 26-week preterm neonate. Lancet Child Adolesc Health. 2020;4(6):476-8.

4 Zeng L, Xia S, Yuan W, Yan K, Xiao F, Shao J, et al. Neonatal early-onset infection with SARS-CoV-2 in 33 neonates born to mothers with COVID-19 in Wuhan, China. JAMA Pediatr. 2020;174(7):722-5.

5 Zimmermann P, Curtis N. COVID-19 in children, pregnancy and neonates: a review of epidemiologic and clinical features. Pediatr Infect Dis J. 2020;39(6):469-77.

6 Franklin D, Fraser JF, Schibler A. Respiratory support for infants with bronchiolitis, a narrative review of the literature. Paediatr Respir Rev. 2019;30:16-24.

7 Pillow JJ, Hillman N, Moss TJ, Polglase G, Bold G, Beaumont C, et al. Bubble continuous positive airway pressure enhances lung volume and gas exchange in preterm lambs. Am J Respir Crit Care Med. 2007;176(1):63-9.

8 Pillow JJ, Travadi JN. Bubble CPAP: is the noise important? An in vitro study. Pediatr Res. 2005;57(6):826-30.

9 Gupta S, Sinha SK, Tin W, Donn SM. A randomized controlled trial of post-extubation bubble continuous positive airway pressure versus infant flow driver continuous positive airway pressure in preterm infants with respiratory distress syndrome. J Pediatr. 2009, 154(5):645-50.

10 Narendran V, Donovan EF, Hoath SB, Akinbi HT, Steichen JJ, Jobe AH. Early bubble CPAP and outcomes in ELBW preterm infants. J Perinatol. 2003;23(3):195-9.

11 Nowadzky T, Pantoja A, Britton JR. Bubble continuous positive airway pressure, a potentially better practice, reduces the use of me- chanical ventilation among very low birth weight infants with respiratory distress syndrome. Pediatrics. 2009;123(6):1534-40.

12 Wax RS, Christian MD. Practical recommendations for critical care and anesthesiology teams caring for novel coronavirus (2019nCoV) patients. Can J Anesth. 2020;67(5): 568-76.

13 Wax RS, Christian MD. Practical recommendations for critical care and anesthesiology teams caring for novel coronavirus (2019. nCoV) patients. Can J Anaesth. 2020;67(5): 568-76.

14 Nolan JP, Monsieurs KG, Bossaert L, Böttiger BW, Greif R, Lott C, et al. European resuscitation council COVID-19 guidelines executive summary. Resuscitation. 2020;153:45-55.

15 Covidien Medtronic. DAR Electrostatic Filter (Small). 2020. Accessed at: https://wwwmedtroniccom/covidien/en-us/products/ mechanical-ventilation/filters/darfiltershtml\#dar-electrostatic-filter-small.

16 Kahn DJ, Courtney SE, Steele AM, Habib RH. Unpredictability of delivered bubble nasal continuous positive airway pressure: role of bias flow magnitude and nares-prong air leaks. Pediatr Res. 2007;62(3):343-7.

17 Vanderbroucke-Grauls CM, Teeuw KB, Ballemans K, Lavooij C, Cornelisse PB, Verhoef J. Bacterial and viral removal efficiency, heat and moisture exchange properties of four filtration devices. J Hosp Infect. 1995;29(1):45-56.

18 Donaldsson S, Naver L, Jonsson B, Drevhammar T. COVID-19: minimising contaminated aerosol spreading during CPAP treatment. Arch Dis Child Fetal Neonatal Ed. 2020; 105(6):669-71.

19 Cheah FC, Darlow BA, Winterbourn CC. Problems associated with collecting breath condensate for the measurement of exhaled hydrogen peroxide from neonates on respiratory support. Biol Neonate. 2003;84(4):338-41.

20 Lee KS, Dunn MS, Fenwick M, Shennan AT A comparison of underwater bubble continuous positive airway pressure with ventilatorderived continuous positive airway pressure in premature neonates ready for extubation. Biol Neonate. 1998;73(2):69-75.
21 Pillow JJ, Neil H, Wilkinson MH, Ramsden CA. Effect of I/E ratio on mean alveolar pressure during high-frequency oscillatory ventilation. J Appl Physiol. 1999;87(1):407-14.

22 Pillow JJ, Wilkinson MH, Neil HL, Ramsden CA. In vitro performance characteristics of high-frequency oscillatory ventilators. Am J Respir Crit Care Med. 2001;164(6):1019-24.

23 Fredberg JJ, Glass GM, Boynton BR, Frantz ID 3rd. Factors influencing mechanical performance of neonatal high-frequency ventilators. J Appl Physiol. 1987;62(6):2485-90.

24 Youngquist TM, Richardson CP, Diblasi RM. Effects of condensate in the exhalation limb of neonatal circuits on airway pressure during bubble CPAP. Respir Care. 2013;58(11): 1840-6.

25 Barranco R, Ventura F. Covid-19 and infection in health-care workers: an emerging problem. Med Leg J. 2020;88(2):65-6.

26 Lavizzari A, Klingenberg C, Profit J, Zupancic JAF, Davis AS, Mosca F, et al. International comparison of guidelines for managing neonates at the early phase of the SARS-CoV-2 pandemic. Pediatr Res. 2020.

27 Heuer JF, Crozier TA, Howard G, Quintel M. Can breathing circuit filters help prevent the spread of influenza A (H1N1) virus from intubated patients? GMS Hyg Infect Control. 2013;8(1):Doc09.

28 Mechanical ventilation of SARS patients. Safety issues involving breathing-circuit filters. Health Devices. 2003;32(6):220-2.

29 Respiratory Care Committee of Chinese Thoracic Society. [Expert consensus on preventing nosocomial transmission during respiratory care for critically ill patients infected by 2019 novel coronavirus pneumonia]. Zhonghua Jie He He Hu Xi Za Zhi. 2020;43(4):288-96.

30 Sprung CL, Zimmerman JL, Christian MD, Joynt GM, Hick JL, Taylor B, et al. Recommendations for intensive care unit and hospital preparations for an influenza epidemic or mass disaster: summary report of the European Society of Intensive Care Medicine's Task Force for intensive care unit triage during an influenza epidemic or mass disaster. Intensive Care Med. 2010;36(3):428-43. 